\title{
Comparison of different blood indices and smear finding among dengue cases: a retrospective review
}

\author{
Pandey S. ${ }^{1}$, Pandey D. ${ }^{2}$ \\ ${ }^{1}$ Dr. Smriti Pandey, Assistant Professor, Department of Pathology, ${ }^{2}$ Dr. Dhruvendra Pandey, Assistant Professor; Department of \\ Community Medicine, both authors are affiliated with Government Medical College, Ratlam, Madhya Pradesh, India.
}

Corresponding Author: Dr. Dhruvendra Pandey, Assistant Professor, Department of Community Medicine, Government Medical College, Ratlam, Madhya Pradesh, India. Email: pandit.dhruv06@gmail.com

\begin{abstract}
Background: Dengue disease is typically found in tropical and subtropical regions, where environmental and socioeconomic conditions favor the development of vector, the mosquito Aedes aegypti. Due to changing climate, urbanization, poor living conditions and inadequate waste management, vector borne diseases like dengue fever are becoming more common. Aims $\&$ Objectives: This study aims to compare different blood indices among the dengue cases. Material \& Methods: A retrospective study among dengue positive cases was conducted at one of the tertiary care centre, Bhopal. Blood sample reports of all the cases from July 2014 to December 2015 was retrieved from records. Total sample size of study was 62 dengue positive cases. All the parameters related to blood smear was recorded and analyzed. The study was approved from institutional ethical committee. Data was analysis using appropriate statistical software. Result: This study included 62 dengue positive cases. In first follow up 41 and in second follow up 28 patients' details was found. Thrombocytopenia was present in $54.8 \%$ cases however $30.6 \%$ cases had platelet count below 50000. Median MPV, PDW and hematocrit were 10.15, 15.85 and 40.35\% respectively. Low MPV ( $<9 \mathrm{fl})$ which indicate bone marrow suppression was observed in $8(12.9 \%)$ patients. High PDW ( $>13 \mathrm{fl})$ which is a useful marker for platelet activation seen in $62(100 \%)$ patients. Conclusion: Laboratory parameters and their regular follow up are essential elements of dengue management. Complete blood picture with some indices may predict the chances of dengue positivity. Appearance of platelet clumps in peripheral smear could be used as an early indicator for severity of disease.
\end{abstract}

Keywords: Dengue, Blood indices, Platelet clumps, Thrombocytopenia

\section{Introduction}

Dengue is a fast emerging pandemic viral disease in many parts of the world especially in tropical and subtropical countries. In recent days there has been an alarming increase in the incidence of dengue fever and has emerged as a serious international public health threat with almost half of the world's population at risk for infection. The disease is also endemic in many parts of India, especially the metropolitan cities and towns. Outbreaks are now reported quite frequently from different parts of the country like rural areas of Haryana, Maharashtra, Andhra Pradesh and Karnataka [1].

Dengue is an arbo viral disease caused by a virus of the genus Flavivirus. There are four serotypes of virus classified as Den-1, 2, 3 and 4. This disease is typically found in areas where environmental and social conditions favor the development of Aedes aegypti mosquito vector [2].

Manuscript received: $14^{\text {th }}$ October 2019

Reviewed: $24^{\text {th }}$ October 2019

Author Corrected: $30^{\text {th }}$ October 2019

Accepted for Publication: $4^{\text {th }}$ November 2019
Most of dengue infections are asymptomatic. Those with symptoms can be classified into 3 patterns, based on their severity; undifferentiated fever, dengue fever (DF) and dengue hemorrhagic fever (DHF) which if accompanied by shock, is called dengue shock syndrome (DSS) [3]. Some clinical and hematological parameters associated with severity of dengue infection may be used to forecast disease severity in patients suspected of dengue infection.

These are Age $>6$ years, female gender, Hematocrit $>40 \%$, platelet $\leq 100,000 / \mu \mathrm{L}$, white cell count $<5,000 / \mu \mathrm{L}$, absolute neutrophil count $<3,000 / \mu \mathrm{L}$ and any bleeding episodes associated with severity of disease $[3,4]$. DF in adults lasts longer than non-dengue febrile illnesses [5]. In india epidemics becoming more frequent and are straining the limited resource of public health system.

There is also paucity of prognostic markers for dengue fever in adults. ${ }^{5}$ Such markers may be particularly useful in determining the necessity for hospitalised care, which would not only reduce the healthcare cost but also aid in the

Pathology Update: Tropical Journal of Pathology \& Microbiology Available online at: www.medresearch.in 863 | P a g e 
appropriate utility of hospital beds [5. The cause of mortality in dengue infection are from prolonged shock, massive bleeding and fliud overload $[5,6,7]$.

As yet, there is no specific treatment for DF and management remains largely supportive, although progress has been made in drug and vaccine development [6].

At present Very few studies have been conducted in central part of our country on dengue infection, hence this study was undertaken to study the significance of clinical picture and laboratory profile of dengue positive cases.

This study principally aims to compare different blood indices among the dengue cases and also find out whether platelet clumping phenomenon was occur before platelet disintegration.

\section{Methodology}

Type of study- Retrospective study

Setting- This study was done in Department of Pathology $\&$ Lab Medicine at one of the tertiary care centre at Bhopal, Madhya Pradesh.

Duration of Study- The total duration of study was 18 months from July 2014 to December 2015.

Sample Size calculation: All cases admitted during the study period was included in the study. Total sample size of study was 62 dengue positive cases.
Sampling Method: All dengue positive patients admitted in the center was included in the study.

Data collection procedure: Blood sample reports of all the dengue confirmed case came to the department was retrieved from records without revealing the identity of the patient.

Blood sample report was prepared with the combination of automated hemotology analyzer reports and smear examination.

All the parameters like platelet count, MPV, PDW, HCT, WBC count and absolute neutrophil count were recorded related to blood smears.

Ethical Consideration and Permission: Ethical approval was obtained from institutional ethics committee.

The confidentiality of the patient was not breached at any point as only reports of all dengue cases was collected and patient identity was not known to either the principal or the co-investigators.

The patient details were not included at any time in the study.

Data Analysis- Data was entered in MS office excel and analyzed with appropriate method.

\section{Results}

In this study, total 62 dengue positive patients were included and analyzed. In first follow up 41 and in second follow up 28 patients' details was found. The patients were both 37 (59.7\%) males and 25 (40.3\%) females ranging from 7 year - 53 years. Mean age of patients was 24.52 years.

Laboratory investigations revealed that thrombocytopenia present in $34(54.8 \%)$ patients (platelet count less than $1,00,000 /$ cumm).

However, in 19(30.6\%) patients platelet count was below 50,000/cumm and only $03(04.83 \%)$ cases had platelet count below $20,000 /$ cumm at the time of presentation.

Median MPV was 10.15 (Range 7.8-14.9), Median PDW was 15.85 (Range 13.9-17.4), Median platelet count was 120000 (Range 13000-351000), Median haemotocrit was $40.35 \%$ (Range $23.60 \%-50.70 \%$ ).

Low MPV ( $<9 \mathrm{fl})$ which indicate bone marrow suppression was observed in $8(12.9 \%)$ patients. High PDW ( $>13 \mathrm{fl})$ which is a useful marker for platelet activation seen in $62(100 \%)$ patients. haemotocrit $>40 \%$ was present in $33(53.2 \%)$ patients.

In this study at the time of first presentation 32 (51.6\%) cases showed WBC count less than $4000 /$ cumm while 44 (71\%) cases had absolute neutrophil count less than 3000/cumm.

The peripheral smears in all these cases were examined, $78 \%$ of the smears showed reactive lymphocytes which are seen as large monocytoid cells. 
Table-1: Demographic and blood indices distribution among dengue positive cases.

\begin{tabular}{|l|c|c|c|}
\hline \multicolumn{2}{|c|}{} & Frequency & Percentage \\
\hline \multirow{4}{*}{ Age (in years) } & $<10$ & 5 & 8.1 \\
\cline { 2 - 4 } & $11-20$ & 19 & 30.6 \\
\cline { 2 - 4 } & $21-30$ & 24 & 38.7 \\
\cline { 2 - 4 } & $31-40$ & 8 & 12.9 \\
\cline { 2 - 4 } & $41-50$ & 4 & 6.5 \\
\hline \multirow{4}{*}{ Sex } & $51-60$ & 2 & 3.2 \\
\cline { 2 - 4 } & Male & 37 & 59.7 \\
\hline \multirow{3}{*}{ Platelet count } & Female & 25 & 40.3 \\
\cline { 2 - 4 } & 550000 & 19 & 30.6 \\
\hline \multirow{3}{*}{ Mean Platelet volumn (MPV) } & $>100000$ & 15 & 24.2 \\
\cline { 2 - 4 } & $<9$ & 28 & 45.2 \\
\hline \multirow{3}{*}{ Hematocrit (HCT) } & $>9$ & 8 & 12.9 \\
\cline { 2 - 4 } & $>40 \%$ & 29 & 87.1 \\
\hline Platelet distribution width & $>40 \%$ & 33 & 53.8 \\
\hline (PDW) & $<13$ & 0 & 0 \\
\cline { 2 - 4 } & $>13$ & 62 & 100 \\
\hline
\end{tabular}

Table-2: Distribution of laboratory parameters among cases.

\begin{tabular}{|l|l|c|c|c|c|}
\hline & & Minimum & Maximum & Mean & Std. Deviation \\
\hline \multirow{4}{*}{$\begin{array}{l}\text { First Presentation } \\
\text { N=62) }\end{array}$} & Age & 7 & 53 & 24.52 & 11.303 \\
\cline { 2 - 6 } & Platelet count counter & 13000 & 351000 & 103661.29 & 73999.323 \\
\cline { 2 - 6 } & Platelet count manual & 20000 & 300000 & 121370.97 & 63918.040 \\
\cline { 2 - 6 } & MPV & 7.8 & 14.9 & 10.355 & 1.4144 \\
\cline { 2 - 6 } & PDW & 13.9 & 17.4 & 15.837 & 0.6356 \\
\cline { 2 - 6 } & HCT & 0.2360 & 0.5070 & 0.407274 & 0.0582646 \\
\cline { 2 - 6 } & WBC Count & 1100 & 9300 & 4196.77 & 1893.3 \\
\cline { 2 - 6 } & Absolute neutrophil & 600 & 6900 & 2619.35 & 1345.77 \\
\hline \multirow{5}{*}{$\begin{array}{l}\text { First Follow up } \\
\text { count }\end{array}$} & Platelet count counter & 14000 & 461000 & 84487.80 & 86098.526 \\
\cline { 2 - 6 } & Platelet count manual & 20000 & 480000 & 100975.61 & 87472.992 \\
\cline { 2 - 6 } & MPV & 8.0 & 12.6 & 10.508 & 1.0102 \\
\cline { 2 - 6 } & PDW & 14.8 & 17.4 & 16.076 & 0.6236 \\
\cline { 2 - 6 } & HCT & 0.3140 & 0.5440 & 0.410366 & 0.0540480 \\
\hline \multirow{5}{*}{$\begin{array}{l}\text { Second Follow up } \\
\text { N=28) }\end{array}$} & Platelet count counter & 16000 & 383000 & 84142.86 & 83787.082 \\
\cline { 2 - 6 } & Platelet count manual & 20000 & 320000 & 88964.29 & 75013.817 \\
\cline { 2 - 6 } & MPV & 8.3 & 14.1 & 10.311 & 1.2515 \\
\cline { 2 - 6 } & PDW & 14.5 & 16.8 & 15.950 & 0.5281 \\
\cline { 2 - 6 } & HCT & 0.3270 & 0.5070 & 0.412857 & 0.0516381 \\
\hline
\end{tabular}

Out of total 62 cases only blood sample of 41 cases came for follow, out of these 41 cases, 33 cases show decreased platelet count. In these 33 cases, 11 (33.3\%) cases had platelet clumps on peripheral smear previously. About 8 patients out of these 41 cases shows increased platelet count on follow up, in all these 8 patients, no one had platelet clumps first time.

As per records, 41 cases that came for first follow up blood, only blood sample of 28 cases come for second follow up. Decreased platelet count seen in 18 cases. Out of these 18 cases platelet clumps was present in $6(33.3 \%)$ cases on peripheral smear previously. 10 cases out of the 28 cases shows increased platelet count, not even single case out of these 10 cases shows platelet clumps in peripheral smear. 


\section{Discussion}

In the present study, there was a slight male preponderance (37 (59.7\%) males and 25 (40.3\%) females). Similar observations have been made by Patel K et al [8], Malthesha MK et al [9], Basir AB et al [7] and Banerjee $\mathrm{M}$ et al [10]. Hypothetically, this can be related to the increased risk of exposure of male gender to mosquito bites due to occupational and recreational activities [8].

The significant laboratory abnormality seen in our patients was thrombocytopenia, as also observed by Malthesa MK et al [9] and $\mathrm{N}$ Ali et al [11]. It was observed that thrombocytopenia was present in $54.8 \%$ patient. Thrombocytopenia is due to the direct and antibody mediated destruction of the platelets and megakaryocytes and also due to the suppression of the bone marrow by virus. [12] Haemorrhagic manifestations are very common with severe thrombocytopenia and severity of haemorrhagic tendency correlates with the platelet counts.

Platelet count was evaluated by automated haematology analyzer as well as on peripheral smear. The analyzer gives a false low reading when platelets clumps are present; such cases were abviated by assessment of platelets on smear.

In this study it was found that there was not even single case with MPV ( $<7 \mathrm{fl})$. high MPV ( $>11 \mathrm{fl})$ were present in 19 (30.64\%) cases and MPV within normal limits (7fl-11fl) were present in 43 (69\%) cases. Study conducted by Bashir $\mathrm{AB}$ et al found that low MPV present in $17.4 \%$ cases, high MPV present in $0.6 \%$ cases, whereas MPV within normal limits present in $82 \%$ cases [7].

In present study low PDW $(<15)$ present in $5(8.06 \%)$ cases, high PDW (>17) found in $4(6.45 \%)$ cases, whereas PDW within normal limits (15-17) found in $53(85.48 \%)$ cases, however study done by Bashir $\mathrm{AB}$ et al [7] found increased PDW in dengue patients.

This study showed that total leukocyte count less than $4000 /$ cumm seen in $51.6 \%$ cases similar finding was suggested by study of Rashmi $V$ et al [13], Arshad et al [14], Vanamali et al [1] and singh $\mathrm{R}$ et al [15] who reported leucopenia in $60 \%, 49 \%, 46 \%$ and $41.4 \%$ of cases respectively. However, studies done by Rusmawati I et al [16] and Dutta P et al [17] found lower incidence of leokopenia that is $33 \%$ and $30 \%$ of cases respectively.

Leucopenia in dengue infection mainly affects the neutrophills and monocyte lineage. It was observed that absolute neutrophill count less than 3000 per cumm in $71 \%$ of cases similar was suggested by Lei HY et al [18] and Kalayanarooj S et al [4]. Atypical lymphocytes were seen in $78 \%$ of total cases. These cells were large monocytoid cell. MV Rashmi et al [13] and Rusmawati et al [16] reported activated lymphocytes in $80 \%$ and $85.1 \%$ of cases respectively. Higher percentage of $93 \%$ was reported by Jameel et al [12]. At present as far there is no study done to find out whether there is presence of platelet clumps seen in peripheral smear in dengue patients prior to platelet destruction, probably their occurrence is due to formation of anti-platelet antibodies in dengue positive cases. This is retrospective study based on the records of patients available at the center. The sample size of study is relatively less which could not predict exact picture of the community.

\section{Conclusion}

This study concluded that each and every blood parameter is important in case of dengue positive patients. In complete blood picture some changes in particular parameter give an indication towards chances of dengue positivity. Similarly, peripheral smear examination is essential in dengue affected areas as some changes in different blood cells gave indication towards positivity.

\section{What the study adds to the existing knowledge?}

This study recommended that use of different blood parameters like Platelet count, haemotocrit, WBC count, ANC along with different platelet indices is essential for early assessment of prognosis as well as to do proper management of dengue cases.

Also, the appearance of platelet clumps could be a early indicator of proceeding platelet depletion and this will help in better management of dengue cases and requirement of platelet transfusion.

\section{Author's contributions}

Dr. Smriti Pandey: Concept, study design, manuscript preparation.

Dr. Dhruvendra Pandey: Data analysis, manuscript preparation

Funding: No funding sources

Conflict of interest: None declared

Ethical Approval: This study was approved by the Institutional Ethics Committee

\section{References}

1. Vanamali DR, Venugopal L, Yeshwanth P, Rampure D. A study on clinical, laboratory profile and outcome of dengue fever. J Evol Med Dent Sci. 2013;50(2):9739-9743.

Pathology Update: Tropical Journal of Pathology \& Microbiology Available online at: www.medresearch.in 866 | P a g e 
2. Souza LJ, Reis AF, Almeida FC, Souza LA, Abukater M, Gomes MA, Abicair OA, Gonçalves PA. Alteration in the erythrocyte sedimentation rate in dengue patients: analysis of 1,398 cases. Brazil J Infect Dis. 2008;12(6):472-475.

3. Pongpan S, Wisitwong A, Tawichasri C, Patumanond J. Prognostic indicators for dengue infection severity. Int $\mathrm{J}$ Clinic Pediat. 2013; 2(1): 12-18. doi: https://doi.org/ $10.4021 /$ ijcp73w.

4. Kalayanarooj S, Vaughn DW, Nimmannitya S, Green S, Suntayakorn S, Kunentrasai N, et al. Early clinical and laboratory indicators of acute dengue illness. J Infect Dis. 1997; 176(2):313-321. doi: 10.1086/514047.

5. Low JG, Ooi EE, Tolfvenstam T, Leo YS, Hibberd ML, $\mathrm{Ng} \mathrm{LC}$, et al. Early Dengue infection and outcome study (EDEN) - study design and preliminary findings. Ann Acad Med Singapore. 2006;35(11):783-789.

6. Normile D. Singapore. Novartis kicks off institute for neglected diseases. Sci. 2003;299(5608):811 doi: 10.1126/ science.299.5608.811.

7. Bashir AB, Saeed OK, Mohammed BA, Ageep AK. Role of platelet indices in patients with dengue infection in Red Sea State, Sudan. Int J Sci Res. 2015;4(1):1573-1576.

8. Patel K, Patel D, Das VK. Hematological Parameters and Its Utility in Dengue fever: A prospective study. Int J Sci Res. 2016;5(4):1077-1079.

9.Malathesha MK, Ashwini HN. Hematological manifestations in dengue fever-An observational study. J. Evol. Med. Dental Sci. 2014;3(9):2245-2250. doi: 10. $14260 /$ jemds/2014/2133.

10. Banerjee M, Chateerjee T, Choudary GS, Srinivas V, Kataria VK. Dengue: A Clinico - Haematological Profile. Med J. Armed Forces India. 2008;64(4):333-336. doi: 10. 1016/S0377-1237(08)80014-7.
11. Ali N, Usman M, Syed N, Khurshid M. Haemorrhagic manifestations and utility of haematological parameters in dengue fever: a tertiary care centre experience at Karachi. Scand J Infect Dis. 2007;39(11-12):1025-1028. Epub 2007 May 30. doi: 10.1080/00365540701411492.

12. Jameel T, Mehmood K, Mujtaba G, Choudhry N, Afzal $\mathrm{N}$, Paul RF. Changing haematological parameters in dengue viral infections. J Ayub Med Coll Abbottabad. 2012; 24(1): 3-6.

13. Rashmi MV, Hamsaveena. Haematological and biochemical markers as predictors of dengue infection. Malays J Pathol. 2015;37(3):247-251.

14. Arshad I, Malik FA, Hussain A, Shah SA. Dengue Fever. Profes Med J. 2011;18(01):57-63.

15. Singh R, Singh SP, Ahmad N. A study of clinical and laboratory profile of dengue fever in a tertiary care centre of Uttarakhend, India. Int J Res Med Sci. 2014;2(1):160163. doi: 10.5455/2320-6012.ijrms20140232.

16. Rusmawati I. Asma Hanim H, Naznin M, Salman MS, Norlelawati AT. A descriptive study of blood films of patients serologically positive for dengue in Hospital Tengku Ampuan Afzan, Kuantan. Int Med J Malaysia. 2010; 9(2):35-37.

17. Dutta P, Khan SA, Borah J, Mahanta J. Demographic and Clinical Features of Patients with Dengue in Northeastern Region of India: A Retrospective CrossSectional Study during 2009-2011. J Virology Microbiol. 2012;786298. doi: 10.5171/2012.786298.

18. Lei HY, Yeh TM, Liu HS, Lin YS, Chen SH, Liu CC. Immunopathogenesis of dengue virus infection. J Biomed Sci. 2001;8(5):377-388. doi: 10.1007/bf02255946.

\section{How to cite this article?}

Pandey S, Pandey D. Comparison of different blood indices and smear finding among dengue cases: a retrospective review. Trop J Path Micro 2019;5(11):863-867.doi:10.17511/jopm.2019.i11.05 